\title{
Measuring Employment Inertia in a Period of Crisis: An Interpretation of Brechling Short-Run Model
}

\author{
Samuel Ambapour \\ Institut National de la Statistique, Brazzaville, Republic of Congo \\ Email: ambapour_samuel@yahoo.fr
}

How to cite this paper: Ambapour, S. (2017) Measuring Employment Inertia in a Period of Crisis: An Interpretation of Brechling Short-Run Model. Theoretical Economics Letters, 7, 939-950. https://doi.org/10.4236/tel.2017.74064

Received: April 10, 2017

Accepted: June 13, 2017

Published: June 16, 2017

Copyright $\odot 2017$ by author and Scientific Research Publishing Inc. This work is licensed under the Creative Commons Attribution International License (CC BY 4.0).

http://creativecommons.org/licenses/by/4.0/ (c) (i) Open Access

\begin{abstract}
In this paper, the Brechling model is used to measure employment inertia in five sectors of the Congolese economy between 1983 and 1993. During that period, the Congolese economy found itself at a crossroad. On the one hand, the implementation of the 1982-1986 five-year economic development plans involved considerable infrastructure investment. On the other hand, given the market reversal observed since 1985, the infrastructure funding and the tempo became less. A structural adjustment program had to be undertaken with the World Bank in 1987-1989 with its measures entirely designed to restore the country's macroeconomic balance and to enable it to resume regular and sustainable growth over time. Thus, the result from the short-run employment model taken over the period in question demonstrates that there is strong employment inertia in the sectors investigated.
\end{abstract}

\section{Keywords}

Partial Adjustment, Desired Employment Level, Employment İnertia, Short-Run Model

\section{Introduction}

Thanks to oil revenues which represented for more than $61 \%$ of national revenues and 36\% of GDP in 1980, the Congo got into a major economic recovery program. One of these objectives was the re-establishment of the public enterprises which were to be the driving force of the economic and social development of the country. For this purpose, considerable financial efforts have been made so that these enterprises have made a significant contribution to job creation. In the mid-1980s, when oil prices collapsed, the Congolese government found itself short of revenues to meet its obligations. The country has borrowed, 
both from the Congolese banks and from foreign bilateral and commercial institutions. Given the magnitude of the problems it faced and the economic repercussions of these problems, the Congolese government was obliged to seek the assistance of the Bretton Woods institutions. The project for the institutional development of public enterprises was thus designed. This project was intended to help the Congo to implement the measures required by the structural adjustment program of 1987-1989 in the context of the recovery of these public enterprises.

In view of all these measures, the present study attempts to evaluate the different ways of the development of employment based on the estimation of a short-term employment model [1]. More precisely, it is a question of describing the existence of a dynamic adjustment process of the actual employment to a desired or technically efficient employment by referring to the costs of turnover of the labor supported by the company when it adjusts its workforce to the current situation. The interest of such a modeling is to identify and to measure the inertia of the employment attached to companies [2].

That said, this paper is organized as follows: the second section presents the short-run employment model. Initially, we describe the partial adjustment process which helps define the employment adjustment speed which lends itself to analysis based on the relative hiring and layoff costs. We also demonstrate that adaptation to desired employment may occur by way of a geometric lag distribution. Then, we present a model specification. We first recall the model application hypotheses in [1]; then, the model is presented in brief as reformulated in [3]. However, the estimation of the model (especially, using macroeconomic data) generally produces a paradoxical result: a yield that increases solely because of the labor factor. To take this observation into account, we adopted a more flexible specification in the end, namely the one proposed in [4] and [5]. Those have shown that under the hypothesis that the expansion path is linear, the short-run relation in [1] can be obtained by inverting the CES function. The third section of the paper is dedicated to an econometric estimation of the model. After the data as well as the estimation methods are briefly presented, the short-run employment model is estimated for the five sectors of the Congolese economy. Our concluding remarks follow in section fourth.

\section{Short-Run Employment Model}

F. Brechling [1] is one of the first economists to estimate a short-run employment function. If we make the simplified assumption that capital stock is exogenous thereby separating investment and short-run employment decisions, it has become customary to follow the work of [1] and to consider employment levels to be a function of production volume, of employment in the previous period, and of time, which represents the technological change trend. In econometric terms, it is an autoregressive model: sought employment levels in the previous period are an additional explanatory variable which helps represent the employment adjustment lag. This is also a partial adjustment model: the exis- 
tence of adjustment costs causes companies not to adjust their staffing at the optimal level. The effective variation in employment corresponds only in part to the optimum variation.

The model in [1], therefore, has the distinction of being dichotomous. The decision making process takes place in two parts [6]: (i) profit maximization which affects the static cost function. The desired or technically efficient employment with respect to which effective employment adjusts itself with a time delay results from the inversion of a Cobb-Douglas-type production function; (ii) an accounting for adjustment costs. The labor demand function is completed by an equation referencing the delayed adjustment process of effective employment with respect to desired employment. This two-step process has the advantage of isolating different economic phenomena: the technology defined by the production function and the adjustment function which is a more "institutional" relation in which behaviors play a part. In addition, it facilitates econometric estimation [7]. This type of modeling is of interest in two ways: (i) in identifying and then measuring the magnitude of employment inertia specific to a company, an industry, and indeed, a country [2]; (ii) in helping understand the behavior of a company with respect to hiring, and in particular, the effect on headcount and market fluctuations that may result from economic policy measures [8].

This model highlights above all short-run mechanisms and primarily, the effect the market environment has on employment. It does not account for phenomena related to the labor/capital substitution. Its frequent use is explained by greater robustness for estimation, on the one hand, and also by it being more flexible, on the other.

\subsection{Partial Adjustment Process}

Let $L_{t}$ represent employees and $L_{t}^{*}$ the optimum level of employment (desired employment). The partial adjustment process highlights the fact that the adjustment of Quantity $L_{t}$ to the desired quantity $L_{t}^{*}$ over a given time period can only be partial because of the cost of employment adjustment and the rigidity of the employment market. The two theoretical reasons set forth in [1] are as follows: (i) very quick fluctuations in employment result in high costs for the company and are impossible to sustain, in fact; (ii) the company is not sure of how stable the demand will be in future periods. In the face of this possibly short-lived growth (or shrinkage) in demand, a company will adopt a cautious behavior, for example, with respect to hiring, all out of fear of layoffs during a period of recession. For these two reasons, the partial adjustment process comes into play:

$$
L_{t}-L_{t-1}=\lambda\left(L_{t}^{*}-L_{t-1}\right) ; 0 \leq \lambda \leq 1 .
$$

Or equivalently: $\frac{L_{t}}{L_{t-1}}=\left[\frac{L_{t}^{*}}{L_{t-1}}\right]^{\lambda} ; \lambda$ is a parameter that describes the speed of adjustment (the opposite of employment inertia). In other words, it measures the speed with which actual headcount variations adjust to the level of "normal" 
headcount variations. This is based on a phenomenon that is well known to French economists and is referred to as the "productivity cycle" [9]: "in a period of general recovery, companies increase their workforces with a lag and (all other things being equal) realize apparent labor productivity gains which are the greater, the smaller the $\lambda$. This results in a shift in the distribution of revenue in favor of the company. In the event of a general economic slowdown, the opposite result is produced." On the other hand, it could be shown that relation (1) is equivalent to an adjustment of employment to its desired level described by a lag model whose parameters follow an infinite geometric distribution [10]:

$$
L_{t}=\sum_{i=0}^{\infty} \lambda(1-\lambda)^{i} L_{t-i}^{*}
$$

In fact, if we defined the lag operator by the relation $E L_{t}=L_{t-1}^{*}$, the expression would turn into (2); thus, $L_{t}=\psi(£) L_{t-1}^{*}$, with:

$$
\psi(£)=\lambda\left[1+(1-\lambda) £+(1-\lambda)^{2} £^{2}+\cdots+(1-\lambda)^{n} £^{n}+\cdots\right]=\lambda /(1-\lambda) £
$$

The partial adjustment process implies two types of costs specified in quadratic form to stay within the constraints for optimizing profit: (i) on the one hand, there clearly exists a cost for failing to adjust to the optimal quantity equal to: $c_{1 t}=a\left(L_{t}-L_{t}^{*}\right)^{2}$; it points either to the existence of idle time related to overstaffing or the use of overtime and/or an increase in work intensity whenever effective staffing is below the optimal value; (ii) on the other hand, the adjustment cost which follows the associated costs with every headcount fluctuation during hiring or layoff phases (hiring includes a training cost while layoff includes indemnity): $c_{2 t}=b\left(L_{t}-L_{t-1}\right)^{2}$. Then, the total cost is as follows:

$$
c T_{t}=a\left(L_{t}-L_{t}^{*}\right)^{2}+b\left(L_{t}-L_{t-1}\right)^{2}
$$

Minimizing the cost determines staffing $L_{t}$. We derive the equation [11]:

$$
\begin{aligned}
& \frac{\mathrm{d} c T_{t}}{\mathrm{~d} L_{t}}=2 a\left(L_{t}-L_{t}^{*}\right)+2 b\left(L_{t}-L_{t-1}\right)=0 \\
& \Leftrightarrow L_{t}(a+b)-a L_{t}^{*}-b L_{t-1}=0 \\
& \Leftrightarrow L_{t}(a+b)-a L_{t}^{*}-(a+b) L_{t-1}+a L_{t-1}=0 \\
& \Leftrightarrow\left(L_{t}-L_{t-1}\right)=\frac{a}{a+b}\left(L_{t}^{*}-L_{t-1}\right) ; 0 \leq \frac{a}{a+b} \leq 1 \\
& \Leftrightarrow\left(L_{t}-L_{t-1}\right)=\lambda\left(L_{t}^{*}-L_{t-1}\right)
\end{aligned}
$$

We see again the expression in (1) with $\lambda=\frac{a}{a+b}$. In the event of low demand, if the layoff cost is high compared to that of maintaining an excessive labor force, for instance, $\lambda$ will be near 0 , and adjustment will be very slow. If, on the other hand, the cost of overstaffing is high along with a relatively low cost of laying off some of the labor force, adjustment will be quick with $\lambda$ approaching 1 . The parameter $\lambda$ being equal to 0.25 , for example, is an indication that a quarter of the difference with optimal staffing is taken away every year. This parameter $\lambda$ also helps calculate the mean adjustment lag which is 
referred to as "productivity cycle length" that is equal to the relation of two costs, i.e.

$$
\Theta=\frac{\psi^{\prime}(1)}{\psi(1)}=\frac{1-\lambda}{\lambda}=\frac{b}{a}
$$

Finally, let us note that the process adopted here is similar to that used in investment theory, that of flexible accelerator.

\subsection{Model Specifications}

There is extensive and controversial literature regarding the short-run relationship between staffing levels and production. The specification first introduced in [1] was critiqued and enhanced by a number of authors. The one adopted here is derived from the ideas in [1] [3] [4] [5] and [12]. We begin by briefly elaborating the hypotheses underlying the short-term employment functions with the problems related to the model specification being addressed next.

\subsubsection{Model Hypotheses}

The short-term employment model essentially rests on the following hypotheses: (i) technology is represented by a two-factor production function:

$$
Q_{t}=A \mathrm{e}^{\rho t} K_{t}^{\beta} L_{t}^{\alpha}
$$

where $Q_{t}$ represents the annual output $t ; L_{t}$ and $K_{t}$ represent labor and capital services in $t$, respectively; $\alpha$ and $\beta$ denote the output elasticity with regard to the labor and capital services, respectively; $\rho$ is the autonomous technological change whose effect is assumed to represent the trend over time; $A$ is a positive constant. (ii) We assume that company supply $(Q)$ determined by the demand funneled towards such companies is exogenous to business people's choices. This implies that, on the one hand, sales are exogenous over the short term. A company cannot act on demand. Moreover, if it is restricted in prospects, it is not restricted in the job market. This set of hypotheses corresponds to Keynesian unemployment. On the other hand, sales determine production levels over the short term in a completely exogenous manner. (iii) Over the short run, capital services are exogenous to business people's decisions, and their evolution is represented by temporal trend $K_{t}=\eta_{0} \mathrm{e}^{\eta t}$ with $\eta_{0}$ being a positive constant. However, the belief that $K_{t}$ evolves in an exogenous manner also requires some very restrictive hypotheses which need to be elaborated [13]: we assume that, firstly, the exogenous factors that determine the evolution of capital stock over the long term are different and independent from those that inform the decision over the short term; secondly, whatever the short-term decision, the one over the long term is always optimal; thirdly, the capital utilization rate is constant and equal to 1; fourthly, capital is homogeneous, and the production function if of type Cobb-Douglas "putty-putty".

\subsubsection{Empirical Specification}

We prefer the way the model was presented in [3] which, incidentally, differs very little from the presentation in [1]. We could re-write Equation (4) as fol- 
lows:

$$
Q_{t}=A \mathrm{e}^{\rho t} K_{t}^{\beta}(L h)_{t}^{\alpha}
$$

where $h_{t}$ is the normal number of productive hours per worker per period. Since $K_{t}$ is exogenous, it can be included in the constant $A$ making the expression (5) become:

$$
Q_{t}=A \mathrm{e}^{\rho t}(L h)_{t}^{\alpha}
$$

A cost function in the form in [3] is associated with the expression (6):

$$
c_{t}=W_{h}(L h)_{t}+F_{t}
$$

$F_{t}$ represents the fixed cost and $W_{h}$ is the wage of a single employee in a period. In addition, the quadratic form was selected for $W_{h}$. That is to say:

$$
W_{h}=a-b h+c h^{2}
$$

By substituting (8) into the cost function, we get:

$$
c_{t}=a(L h)_{t}-b L_{t} h_{t}^{2}+c L_{t} h_{t}^{3}+F_{t}
$$

For the sake of brevity and without loss of generality, we can derive $h_{t}$ from (6) and include it in (9), and minimizing this last expression, we get the desired level of staffing which, when combined with (1) produces the regression equation in [1], in the end:

$$
\log L_{t}=a_{0}-\frac{\lambda \beta}{\alpha} t+\frac{\lambda}{\alpha} \log Q_{t}+(1-\lambda) \log L_{t-1}
$$

where $a_{0}=\lambda \log \left[\frac{2 c}{A^{1 / \alpha} b}\right]$.

We can re-write (10) more simply. That is to say:

$$
\log L_{t}=a_{0}+a_{1} t+a_{2} \log Q_{t}+a_{3} \log L_{t-1}
$$

with $a_{1}=\lambda \rho / \alpha ; a_{2}=\lambda / \alpha ; a_{3}=1-\lambda$. Most macroeconomic estimates made on the basis of the regression in (11) reveal an increase in yield based only on the labor factor: a value of $\alpha$ much greater than unity. This result considered to be paradoxical, on the one hand, puts into question the theoretical foundations of the basic model with profit maximization criteria and, on the other hand, has given rise to lively interest in the research and the interpretation of the above result. Regarding this last point, we can name a few attempts at explanation proposed in literature [5] [6] [8]: (i) the distinction between direct and indirect labor. Here, we assume that a part of the employment is variable over the short term, and the complement not affected by general fluctuations may be likened to a quasi-fixed factor. The estimation of the short-term function on all the headcount values would then result in an overestimation of productivity; (ii) failure to take into account short-term fluctuations in equipment utilization. Under these conditions, any change in production originates exclusively in a change in labor services; (iii) measurement error. We assume that the various measurement errors having to do both with output and employment may introduce a bias into the estimation results. 
In [14], this discussion is summarized in the following terms: the various explanations that were sought for this debate are based on the common conviction that the difficulty stems from problems in accounting for the factors' utilization levels and in specifying the trends involved with the employment functions. However, model refinement has not helped obtain significantly better results so far. An advance has, nonetheless, been made, especially with the work in [4] and [5]. These two authors have proposed an alternative specification and shown that if we postulate the hypothesis that the expansion path is linear and demand only the long-term complementarity of the labor and capital utilized, the relation in [1] could be obtained by inverting the CES function which is homogeneous in degree $v$ :

$$
Q_{t}=A \mathrm{e}^{\rho t}\left[a(L h)_{t}^{-\omega}+(1-a)(K u)_{t}^{-\omega}\right]^{-v / \omega}
$$

where $K u$ is the capital used. Once again without going into detail, the process borrowed by the two authors led to the following definition of desired employment:

$$
L_{t}^{*}=Q_{t}^{1 / v} \mathrm{e}^{-(\rho / v) t} G
$$

where $G$ is a constant. Combining (13) with (1), we obtain:

$$
L_{t}=G^{\lambda} \mathrm{e}^{-\rho \lambda t / v} Q_{t}^{\lambda / v} L_{t-1}^{1-\lambda}
$$

whence the regression equation:

$$
\log L_{t}=G-\frac{\lambda \rho}{v} t+\frac{\lambda}{v} \log Q_{t}+(1-\lambda) \log L_{t-1}
$$

(15) can be written exactly as (11) with $a_{1}=-\lambda \rho / v ; a_{2}=\lambda / v ; a_{3}=1-\lambda$; however, the coefficients interpret differently: $\left(1-a_{3}\right) / a_{2}=\alpha$ is the work productivity in (11), whereas $v$ is return to scale in (15); $-a_{1} / a_{2}$ represents in (11) the output growth rate from the combined effect of capital growth and technological change, and in (15) solely the effect of technological change. In the expression (15), the employment demand function shows that over the short term, production-related employment elasticity is equal to $\lambda / v$. On the other hand, over the long term, employment adjustments have time to occur in their entirety: long-term employment/production elasticity is greater, equal to $1 / v$, that is to say, equal to the inverse of the scale parameter. If we were to exclude the parameter $\lambda$ which characterizes the short-term imbalance, we could note that employment depends on two factors in the relation (15): (i) a positive factor measured by the long-term labor elasticity $1 / v$ with respect to production; (ii) the effect of technological change $-\rho / v$ which plays negatively from the standpoint of required labor savings whatever happens to demand.

\section{Econometric Estimation}

\subsection{Data}

The data was provided by the Congolese National Institute of Statistics. These are estimations made from the results of annual and market investigations at 
public and private companies. They have to do with five sectors of the Congolese economy over a period from 1983 to 1993. There are five sectors: (i) syviculture and forestry; (ii) manufacturing; (iii) power generation and water; (iv) construction and public works; (v) transportation and telecommunications. For the five sectors investigated, we note a labor force that is reduced overall by $16 \%(15 \%$ for syviculture and forestry, water and power generation, $65 \%$ for construction and public works, and $18 \%$ for transportation and telecommunications).

The only growth observed (29\%) was in the manufacturing sector. A visual summary can be found in Figure 1. Let us note that in the mid-80s, the Congolese State was at a crossroads. On the one hand, the implementation of the 19821986 five-year economic development plan involved considerable infrastructure investment. On the other hand, given the market reversal observed since 1985, the infrastructure funding and the tempo became less. Given the magnitude of the events facing it and these problems' economic repercussions, the Congolese Government had to request assistance from the Bretton Woods institutions. Thus, there was a need to undertake a structural adjustment program one of whose objectives was to rehabilitate key public companies to improve their performance and whose subsequently identified problems essentially had to do with the human factor (lack of motivation, discipline, training), excessive costs (staffing), organization, and management.

\subsection{Estimation Method}

The data that we have at our disposal include two dimensions: an individual dimension and a temporal dimension (cross-section and time series data). In an econometric treatment of this type of data, the individual dimension is generally higher than the temporal one. But there is nothing that prevents us from being able to observe a small number of units over a long period: this is the type of data in our study. Similar examples of data abound throughout literature [15]. In general, individual temporal data require that new econometric procedures be developed [16]. Thus, the nature of the data and the autoregressive character of

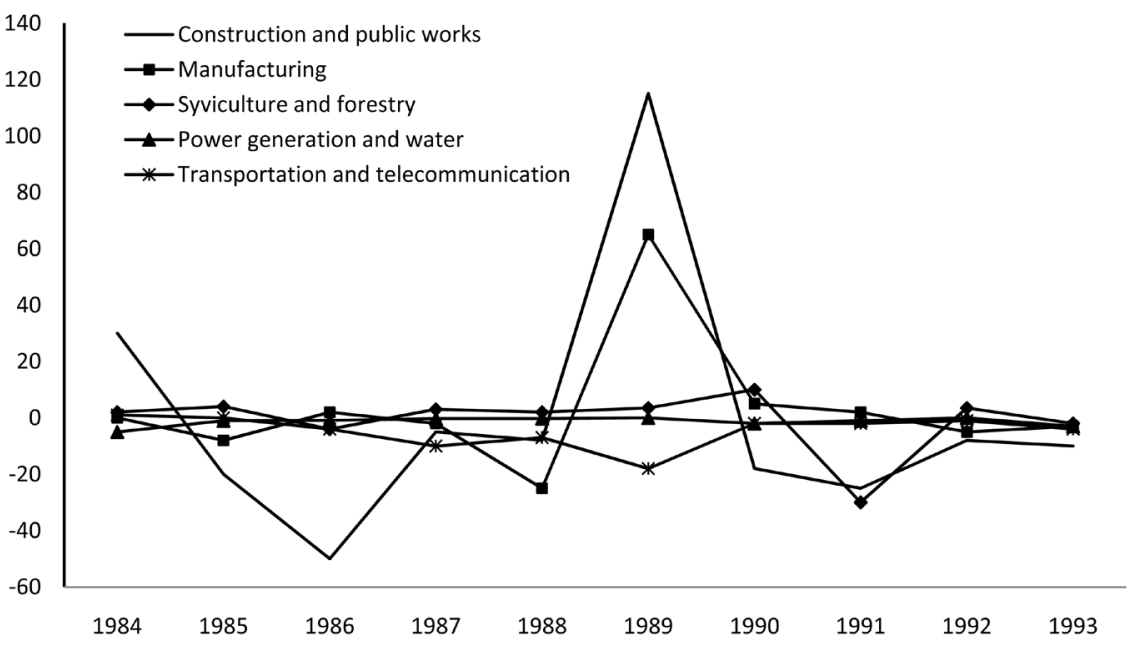

Figure 1. Employment growth (\%). 
the model make us adopt certain simplified hypotheses regarding the structure of the covariance matrix of the residual terms of the model. To accomplish this, we use the method in [17] [18] which is an extension of the method in [19] to the case where the residuals follow a first-order Markovian process [20] [21].

\subsection{Results}

Before giving the model estimation results, it is worth noting that, in order to understand certain economic realities and to be inspired by the work of [2], attempts to improve this specification were made by introducing dummy variables. These are dichotomous variables taking only two values: 0 and 1 . Thus, given that the stock of capital does not appear in the model, the hypothesis of introducing a specific constant per sector has been tested. The same has been done for the employment behavior before and after the application of the measures of the structural adjustment program. Unfortunately, all these regressions were considered "globally not significant".

When Equation (15) is estimated over the period from 1983 to 1993, it yields the following results:

$$
\begin{gathered}
\log L_{t}=-1.92324-0.0113 t+0.12696 \log Q_{t}+0.87326 \log L_{t-1} \\
(-2.99) \quad(2.143) \quad(16.936) \quad(2.219) \\
R^{2}=0.97646 ; \quad F=636.08
\end{gathered}
$$

The values in parenthesis are $\mathrm{t}$-statistics. It can be observed that all the coefficients are statistically significant at the $5 \%$ level. The model's explanatory power, on the other hand, is excellent judging from the coefficient of determination which indicates that the variance in employment is explained at about $98 \%$. The identification of regression coefficients for the structural parameters in the employment equation helps arrive at an estimate of the speed of adjustment $\lambda$ of the scale factor $v$ and of the technological change $\rho$. We find that $\lambda$ is equal to 0.127 . Therefore, we conclude that the behavior of private and public Congolese companies in the five sectors of the economy of interest was dominated by strong employment inertia. The adjustment of effective employment to the desired staffing levels over the period investigated occurred at a rate of $12.7 \%$ a year.

\subsection{Discussion}

The result obtained with respect to employment inertia is comparable to that obtained in a goodly number of papers already written on the subject, namely those written by [2] regarding public Senegalese companies between 1980 and 1988: $\lambda$ equal to either 0.117 or 0.129 depending on the group of companies investigated. Since inertia points to the effect of both technological and institutional factors at the same time, two types of explanations are frequently advanced to interpret these results which we believe to capture the Congolese case rather well. In general, the reasoning holds for the public sector given that the private sector is naturally developed to a very small degree. According to the two 
authors quoted above, there is first trade union action to save jobs in periods of slow growth, the will of social partners to manage for the lowest human cost of corporate recovery. Also, in the case of interest to us, the Government and trade unions agreed, as part of a structural adjustment program, progressively to reduce the headcounts at large public companies more through a hiring freeze than through layoffs. The strategy of this measure is now known: it results in insufficient demand and to degraded productivity. In addition, we mention the existence of legal hurdles as the second explanatory factor. Employment adjustment follows the internal rules and the institutional constraints that govern the public sector employment markets [22]. Personnel at public companies enjoys employment protection comparable to a degree to that of civil servants.

On the other hand, we note an almost unitary return to scale: $v=1.003$. This is a rather surprising result given that in a country's economy, there are monopolies with natural monopolies operating at increasing returns being the extreme case. This result could also be placed in doubt if we were to recall the fact that the Congo is classified as a middle-income economy. In fact, according to the line of reasoning developed by [23], "in the first stage of the development process, the technical indivisibilities of investment and the will of the powersthat-be to generate the highest momentum for activities that are directly productive are frequently a factor in creating economic and social infrastructure overcapacity." In the absence of a clear and straightforward explanation, this result could be attributed to the heterogeneity that seems to be a characteristic of the sectors.

The identification of the parameter $\rho$ results in a fairly high estimated value for the rate of technological change, on the order of $13 \%$ (12.9 to be more exact). Again, this result is comparable to that obtained for public companies in Senegal: $\rho=15 \%$. Same as when interpreting other parameters, here, we also have to settle for conjectured explanations. First, the hypothesis of an overstated rate of technological change cannot be discarded. Then, it could be noted that during a period of structural adjustment, given the tighter budgetary constraints, more has to be done with less; this individual behavior theory based on a methodological hypothesis of bounded rationality [24] [25] implies that the search for efficiency X could constitute a potentially explanatory factor [2] in our case.

\section{Conclusions}

In the early 1980s, considerable financial resources were provided for the recovery of public enterprises in the Congo. As a result, these companies have made a significant contribution to job creation, opening up the hinterland and improving the living standards of the population. However, these positive aspects have had a very negative financial result. It was necessary to subscribe to the structural adjustment program in 1986. The objective of this article was therefore to evaluate the measures implemented by examining the employment-production relationship. Thus, the short-term employment equation was estimated for five sectors of the Congolese economy over the period 1983-1993. The result ob- 
tained shows that the speed of employment adjustment was low over the time period in question.

Although the explanatory power of the model in question is good, the present study has some limitations which can be the scope for future research: (i) the model places employment determination solely within the context of Keynesian unemployment. This hypothesis is not completely verified yet for the sectors investigated even though it is true that some public companies lay the foundations of the economic infrastructure by making heavy investments; (ii) classically, the added value is a labor function rather than the inverse as assumed by the short-term employment model. Tests of this variable for exogeneity within the models are not always conclusive; (iii) macroeconomic data from developing countries are frequently subject to uncertainty which is not without consequence for econometric estimations.

\section{Acknowledgements}

The author would like to thank editor and anonymous reviewers for their constructive comments. Nonetheless, he is solely responsible for any errors and omissions in this study.

\section{References}

[1] Brechling, F. (1965) The Relationship between Output and Employment in British Manufacturing Industries. Review of Economic Studies, 32, 187-216. https://doi.org/10.2307/2295824

[2] Lesueur, J.Y. and Plane, P. (1993) Politique de l'emploi et évolution de la productivité dans les entreprises publiques sénégalaises (1980-1988). Annales de l'Economie Publique Sociale et Coopérative, 3, 395-418.

https://doi.org/10.1111/j.1467-8292.1993.tb01755.x

[3] Ball, R.J. and Saint Cyr, B.B.A. (1966) Short Term Employment Functions in British Manufacturing Industries. Review of Economic Studies, 33, 179-207.

https://doi.org/10.2307/2974413

[4] Smyth, D.J. and Ireland, N.J. (1967) Short Term Employment Functions in Australian Manufacturing. Review of Economic and Statistics, 537-554. https://doi.org/10.2307/1928339

[5] Ireland, N.J. and Smyth, D.J. (1970) The Specification of Short Run Employment Models. Review of Economic Studies, 37, 281-285. https://doi.org/10.2307/2296420

[6] Cohen-Skalli, B. and Lascar, D. (1980) Fonctions d'emploi à court terme et cycle de productivité. Annales de l'INSEE, 38-39, 123-152. https://doi.org/10.2307/20076389

[7] Guilhon, B. and Roos, J.-L. (1983) L'ajustement à court terme de l'emploi à la production: Des relations techniques aux fonctions de comportement. Revue Economique, 4, 732-755. https://doi.org/10.2307/3501139

[8] Cette, G. (1986) Les rendements de travail dans les fonctions d'emploi de court terme. Cahiers Economiques et Monétaires, 22, 3-65, Banque de France.

[9] Boyer, R., Mazier, J. and Olive, G. (1974) Un nouveau modèle macroéconomique STAR. Economie et Statistique, 61, 29-53. https://doi.org/10.3406/estat.1974.1685

[10] Muet, P.A. (1979) Les modèles à retards échelonnés: Fondements théoriques, spécifications et méthodes d'estimations usuelles, Cahiers du Groupe de Mathématiques Economiques, 2. Université de Paris I. 
[11] Sevestre, P. (1988) Econométrie II, Polycopié ENSAE. Malakoff.

[12] Brechling, F. and O'Brien, P. (1967) Short-Run Employment Functions in Manufacturing Industries: An International Comparison. Review of Economics and Statistics, 49, 277-287. https://doi.org/10.2307/1926639

[13] Catinat, M. and Verger, D. (1980) Estimation de modèle de travail à court terme. Annales de I Inséé, No. 38-39, 153-175. https://doi.org/10.2307/20076390

[14] Dormont, B. (1986) Les ajustements de l'emploi dans la crise en France et en RFA. Une étude sur les données d'entreprises industrielles françaises et allemandes sur la période 1967-1979. Revue d Economie Politique, 96, 256-280.

[15] Greene, W.H. (2000) Econometric Analysis. Prentice Hall, Upper Saddle River.

[16] Mazodier, P. (1993) Econométrie II, Polycopié ENSAE. Malakoff.

[17] Parks, R.W. (1967) Efficient Estimation of a System of Regression Equation When Disturbances Are Both Serially and Contemporaneously Correlated. Journal of American Statistical Association, 62, 500-509. https://doi.org/10.1080/01621459.1967.10482923

[18] Kmenta, J. and Gilbert, R.F. (1968) Estimation of Seemingly Unrelated Regressions. Journal of the American Statistical Association, 63, 1180-1200. https://doi.org/10.1080/01621459.1968.10480919

[19] Zellner, A. (1962) An Efficiency Method of Estimating Seemingly Unrelated Regressions and Test for Aggregation Bias. Journal of the American Statistical Association, 57, 348-368. https://doi.org/10.1080/01621459.1962.10480664

[20] Greene, W.H. (1997) LIMDEP, Econometric Software. Prentice Hall, Upper Saddle River.

[21] White, K.J. (1997) Shazam, Econometric Computer Program, User's Reference Manual, Version 8. McGraw-Hill, New York.

[22] Chambas, G., Lesueur, J.Y. and Plane, P. (1995) Les Relations Salaires, Emplois Productivité. In: Vernieres, Ed., Ajustement, Education et Emploi.

[23] Hirschman, A.O. (1958) The Strategy of Economic Development. Yale University Press, New Haven.

[24] Leibenstein, H. (1978) X-Inefficiency Theory and Economic Development. Oxford University Press, London.

[25] Plane, P. (1997) Efficience technique et développement. Introduction. Revue d Economie de Développement, 3, 3-7. 
Submit or recommend next manuscript to SCIRP and we will provide best service for you:

Accepting pre-submission inquiries through Email, Facebook, LinkedIn, Twitter, etc. A wide selection of journals (inclusive of 9 subjects, more than 200 journals)

Providing 24-hour high-quality service

User-friendly online submission system

Fair and swift peer-review system

Efficient typesetting and proofreading procedure

Display of the result of downloads and visits, as well as the number of cited articles Maximum dissemination of your research work

Submit your manuscript at: http://papersubmission.scirp.org/

Or contact tel@scirp.org 